Books, videos, cd-roms, dvds and any other relevant items submitted for a review in the BDJ should be addressed to:

Mike Grace, Editor, British Dental Journal, 64 Wimpole Street WIG 8YS

\section{Restorative dentistry}

\author{
A. D. Walmsley, T. F. Walsh and F. J. T. Burke \\ Edinburgh: Churchill Livingstone, 2002 \\ Price $€ 37.99$ \\ ISBN 0443059853
}

All of restorative dentistry, in one volume of 200 pages? Surely it cannot be done? The editor and authors certainly took on a tall order in trying to accommodate and integrate all dimensions of the discipline in one fairly slim book. In truth, the order was perhaps a little too tall for comfort.

Although there is quite a lot that is good, I fairly quickly found myself wondering at whom it was aimed. My first thought, as I worked my way through the early chapters, was that it was an introductory text for the junior student. The section on examination and treatment planning was certainly the sort of thing that a second or third year student might find quite helpful. The subsequent chapters on periodontology contained some good sections on instrumentation and were straightforward, clear and mostly appropriate to a junior undergraduate student, though with a little too much oral medicine. It was when I reached occlusion that I started to become confused about the intended audience; we were into pantograph tracings before I knew what was going on, and this was the first of a number of areas where the depth extended well beyond the junior undergraduate level. By contrast, some areas are barely covered at all. The only material on complete dentures, for example, is in the small sections on implants and the rather good section on overdentures. As we are still some way from a world where the principles of complete denture construction are redundant, something on complete dentures would surely be appropriate. One other curious omission is the small amount of attention paid to cariology. In fact the 13 well illustrated chapters cover most of the major themes of restorative dentistry but inconsistency of depth is a recurring theme. Some areas assume an existing background knowledge, where others lead the reader through the absolute basics.

There is quite a lot that is good; the illustrations are numerous, varied and well reproduced; individual chapters and sections sometimes hit the mark, those on endodontics, veneers and resin bonded bridges are particularly worthy of mention. Overall though, there is more of an emphasis on the technical and technological rather than the biological, whilst the style tends to be a little more prescriptive than reflective. The aim is laudable, and there is no doubt that undergraduate students will love the idea of having everything they need to know about restorative dentistry in a single book. However, I think this falls some way short of being a comprehensive text and I am still no clearer at whom it is really aimed.

\section{J. Steele}

\section{Essentials of dental radiography and radiology}

\section{E. Whaites \\ Edinburgh: Churchill Livingstone, 3rd edition, 2002 Price $£ 34.99$}

ISBN $044307027 x$

This is the 3rd edition of an excellent book on dental radiography and radiology which has been at the forefront of publications in this field since it first appeared in 1992. Eric Whaites has taken the opportunity to revise sections of the book, following the introduction of new regulations controlling the use of ionising radiation in the UK, to ensure that the trainees and practitioners who use it will be up to date. He has also replaced many of the photographs to ensure that they are completely up to date with current recommendations with regard to radiation protection, and included a larger number of examples of pathology. The bibliography and suggested reading has been considerably expanded.

The chapter on radiation protection will be invaluable to all students and practising dentists wishing a clear and concise presentation of the regulations. Whilst some of the points are only relevant to law in the UK, many of the 'good practice' statements will be of relevance to dentists and dental students throughout the world. Eric has taken the opportunity to provide a very clear summary of points requiring action, and to give a clear and understandable explanation of the responsibilities of the people involved in an X-ray examination. The different categories of radiographic examination and the justification for these categories is well covered, with good common sense advice in relation to examinations that may be desirable primarily for research or medico-legal reasons. There is still a need for practitioners to read the Guidance notes for dental practitioners on the safe use of $x$-ray equipment, but having read this chapter, they will find no problem in following the regulations and recommendations which are contained in them. Reference to the regulations is made elsewhere in the text, with particular emphasis placed on the importance of the mandatory establishment of quality assurance procedures. Clear guidance on this issue is given in chapter 16 .

A number of other changes are worthy of comment: the table on risk is presented in a more user-friendly way than previously, and will be of real value to dentists who get asked this question; illustrations of equipment and controls have been replaced in order to show current machines; the infection control procedures have been expanded, and now incorporate eye protection and CCD digital sensors.

The section on periapical radiography has been completely re-illustrated, and 


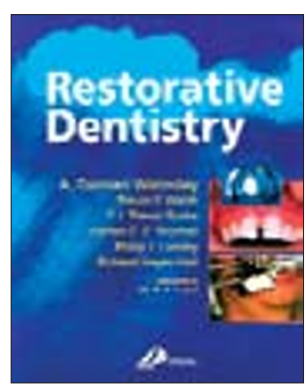

is now clearer, with the procedures for a single tooth/area on one page for paralleling technique. The illustrations for bisected angle now show disposable film holders as well as the traditional finger method of supporting the film. In the chapter on panoramic radiography the author refers to the FGDP publication, Selection criteria in dental radiology, in his introduction to the indications for this view. This is useful as it reinforces the need to have a clear justification for all radiographic examinations. Acknowledging the increase in use of digital imaging systems, the section dealing with dental digital imaging has been considerably expanded.

This book continues to be an excellent publication and one which many people will wish to have on their shelves and in their libraries.

\section{Brocklebank}

\section{Endodontics}

Ingle and Bakland

BC Decker Inc., 5th Ed, 2002

Price 129.95 USD

ISBN 1550091883

This is the fifth edition of a book first published in 1964. On the first page the authors observe that endodontics has to be the ultimate in limited (medical) specialties, and pose the question 'How could one write 900 pages about the inside of the tooth?'

The answer is that this is a book which, like flopsy, has grown and grown. The first edition was 650 pages, and much of the text, and several of the illustrations, are still present in the latest edition. The first edition contained several hundred references, the latest several thousand. The first edition had 22 contributers, and the latest has 55 , providing expertise from every field of the subject.

This is a book for the specialist endodontist, and the postgraduate
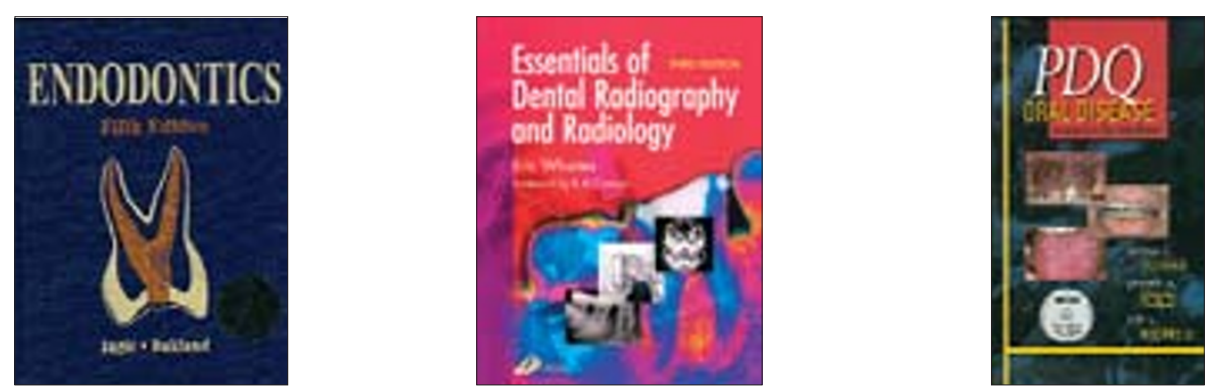

student, who wish to research the history and development of endodontology from its early days to the very latest techniques. A casual reader may find facts presented which are subsequently disproved as the text develops, and may then question why they were included. An example would be in the chapter on obturation, almost 100 pages long, which makes frequent reference to the use of silver points. Indeed, this may be the only modern endodontic textbook to still advocate their use, even if only for elderly patients who may not expect too long a prognosis.

The descriptions of modern endodontic procedures are excellent, although it is a shame the publishers chose not to use colour in the illustrations. However, the book does include a compact disc from which the entire text and illustrations may be loaded on to a computer, and accessed by all users. Obviously it is not possible to copy sections or illustrations, but parts may be printed if required.

I learned much from my review, and this book is certainly a treasure-trove for anyone with a passion for endodontics.

P. Carrotte

\section{PDQ in oral disease diagnosis and treatment}

\author{
J. Sciubba, J. Regezi and R. Rogers \\ BC Decker, 2002 \\ Price 59.95 USD \\ ISBN 1550092189
}

This pocket sized book takes the PDQ series into non-dental oral disease with a well presented and illustrated volume. A feature of the PDQ books is to provide all of the text and photographs on a mini CD ROM included in the book purchase price. Sensibly these are presented in Acrobat format to prevent piracy.

The authors have backgrounds in ENT, oral pathology and dermatology and this is often reflected in the text where the information is 'slanted' towards the specialty of the contributing author. The format of the book is similar to other pocket atlas guides with a photograph and note-form text reviewing a specific oral condition over two pages. However the inclusion of a comprehensive section of contemporary papers and books with further reading for each section of the book is welcome; the core information is often scanty to aid a quick 'scan' of the key disease features. However this core is presented clearly and in a well organised form and although it is not a text that could be used alone for exam revision, it will be helpful as an instant 'on the clinic' review for both the student and junior clinician alike.

Where this book fails however, is as an aid to patient management. The treatment options provided are brief and often unhelpful. This contrasts badly with the ample pathological information and differential diagnostic possibilities suggested. A 'prognosis' is suggested for each of the conditions described, but this is at best unhelpful and most often so concise as to offer no useful information to the reader. A competent therapeutics section attempts to supplement this limited clinical management information, but being a text aimed at the north American market, the authors' recommendations must be considered with caution in other countries where drug product licences and acceptable therapeutic regimes may differ.

This book does have its merits - a wider range of topics are covered than in many similar pocket atlases and the suggested reading is very helpful. It may have a market with physicians and specialists who occasionally require core information about a specific oral condition. However there are many alternatives available and the prospective dental purchaser must be clear whether they wish a book offering predominantly background information or a more helpful clinical management guide.

A. Crighton 